\title{
INCIDÊNCIA DE ÓBITOS POR SEPSE EM NEONATOS
}

DOI: $10.22289 / 2446-922 X . V 4 N 3 A 3$

\section{RESUMO}

\author{
Larissa Mariana Silva ${ }^{1}$ \\ Elizaine Aparecida Guimarães Bicalho \\ Ana Carolina Magalhães Caixeta
}

\begin{abstract}
A sepse é a principal causa de óbito em pacientes neonatos em todo o mundo. A sepse neonatal pode ser classificada como precoce, que procede da contaminação do recém-nascido por bactérias transmitidas no canal de parto, ou de uma contaminação secundária a bacteremias maternas. E sepse tardia que é responsável principal pela internação prolongada e pela mortalidade de recém-nascidos internados nas unidades de terapia intensiva. O objetivo deste estudo foi identificar a incidência e causas de óbitos por sepse precoce e tardia em neonatos. Trata-se de uma pesquisa de natureza Estatística, descritiva e analítica, de abordagem quantitativa, a ser realizada através da avaliação dos dados contidos no banco de dados da Secretaria Municipal de Saúde - DATASUS. O estudo estatístico, com revisão narrativa conceitual, de caráter descritivo, é de extrema importância para que os profissionais atuantes em UTIs Neonatais tenham condições de identificar de forma rápida e adequada se a sepse neonatal precoce e tardia, para que assim possam colaborar e garantir que os recém-nascidos recebam um tratamento adequado. Os resultados obtidos mostraram que a sepse neonatal tardia ainda é uma condição clinica responsável por um grande número de óbitos em neonatos prematuros e os neonatos do sexo masculino tem maior risco para o óbito.
\end{abstract}

Palavras-chave: Enfermagem; Neonatos; Sepse.

\section{ABSTRACT}

Sepsis is the leading cause of death in neonatal patients worldwide. Neonatal sepsis can be classified as precocious, resulting from the contamination of the newborn by bacteria transmitted in the birth canal, or from contamination secondary to maternal bacteremias. And late sepsis is the main cause of prolonged hospitalization and the mortality of newborns hospitalized in intensive care units. The objective of this study was to identify the incidence and causes of early and late sepsis deaths in neonates. This is a Statistical, descriptive and analytical, quantitative approach, to be performed through the evaluation of the data contained in the database of the Municipal Health Department - DATASUS. The statistical study, with descriptive narrative review, is extremely important for professionals working in Neonatal ICUs to be able to quickly and adequately identify early and late neonatal sepsis so that they can collaborate and ensure that newborns receive appropriate treatment. The results showed that late neonatal sepsis is still a clinical condition responsible for a large number of deaths in preterm neonates and male neonates are at higher risk for death.

Keywords: Nursing; Neonates; Sepsis.

\footnotetext{
1 Endereço eletrônico de contato: larissamariana278@hotmail.com

Recebido em 25/09/2018. Aprovado pelo Conselho Editorial e aceito para publicação em 31/10/2018.
}

Rev. Psicol Saúde e Debate. Dez., 2018:4(3):20-31. 


\section{INTRODUÇÃO}

A sepse é um quadro clínico complexo e de alta gravidade, em que há uma resposta inflamatória sistêmica descontrolada e de origem infecciosa, que se manifesta de várias formas no indivíduo, causando-lhe disfunção ou falência de órgãos, que podem levar à morte (Carvalho, \& Trotta, 2003).

Considerada como uma das principais causas de morte dentro das Unidades de Terapia Intensiva (UTI), ela representa um desafio da medicina e da saúde no país, uma vez que devido a suas complicações, o índice de mortalidade entre os pacientes sépticos no Brasil é de cerca de 46,6\% (Sales Júnior et al., 2006).

A sepse, também referida como infecção na corrente sanguínea, bacteremia, septicemia e infecção generalizada, representa uma condição que importa em grave risco de vida, tida como a infecção de maior impacto no período neonatal, por apresentar taxas de letalidade elevadas e ao se instalar evolui progressivamente, sendo difícil conseguir reverte-la (Souza, 2015).

Quando no nascimento ou ainda na vida-uterina, o feto é exposto à contaminação por microrganismos presentes no canal de parto, pertencentes à flora genital materna. De mesmo modo, o ambiente hospitalar ou domiciliar também pode ser responsável pela colonização de bacterianas potencialmente causadoras de sepse, podendo ocorrer surtos epidêmicos de sepse neonatal em unidades de prematuros ou de terapia intensiva neonatal (Ceccon et al., 2000).

Conceituada como há apresentação de bacteremia, acompanhada do comprometimento hemodinâmico e de sinais sistêmicos de infecção, quando ocorrida no período entre o nascimento e 28 dias de vida, a septicemia neonatal divide-se em duas classificações: sepse neonatal precoce e sepse neonatal tardia. A primeira verifica-se quando os sintomas se manifestam dentro de sete dias após o nascimento e a segunda quando o quadro surge sete dias após o parto (Benincá et al., 2013).

A sepse neonatal precoce é a infecção sistêmica que se manifesta em até 72 horas após o nascimento, comumente relacionada a fatores de risco materno, apresentando diversas manifestações clínicas e laboratoriais. Sabe-se que infecções maternas, sobretudo as do trato genito-urinário, representam fatores de risco na sepse neonatal, uma vez que se vislumbra seu aumento em pacientes em que as genitoras apresentaram algum tipo de infecção no período gestacional, independente da época (Goulart et al., 2006).

Na sepse neonatal, parte da suposição de que na vida intrauterina e/ou no nascimento o feto pode ficar exposto à contaminação por microrganismos presentes no canal de parto, pertencentes à flora genital materna. De mesmo modo, o ambiente hospitalar ou domiciliar também pode ser responsável pela colonização de bacterianas potencialmente causadoras de 
sepse, podendo ocorrer surtos epidêmicos de sepse neonatal em unidades de prematuros ou de terapia intensiva neonatal (Ceccon et al., 2000).

Já na sepse tardia, como dito, os sintomas ocorrem a partir do quarto dia de nascimento (após 72 horas de vida), e está diretamente ligada a fatores neonatais, acometendo normalmente recém-nascidos internados nas UTI Neonatal. Neste caso, a septicemia ocorre em razão da contaminação por micro-organismos através do contato humano, indireto com o ambiente contaminado, razão pela qual, para evitá-la, são necessárias intervenções preventivas para minimizar a exposição aos recém-nascidos (Silva et al., 2015).

A Unidade de Terapia Intensiva (UTI) refere-se a um ambiente equipado de aparelhamentos especiais que oferecem assistência médica e de enfermagem especializadas competentes a disponibilizar tratamento a pacientes graves (Salicio, \& Gaiva, 2006).

Semelhante a UTI tradicional, tem-se a Unidade de Terapia Intensiva Neonatal (UTIN), que se reserva ao atendimento de recém-nascidos de alto risco, cujo fim é dar assistência para garantir melhores condições à sobrevivência dos bebês. Na UTIN, são observados, permanentemente, pela equipe de saúde, parâmetros cardíacos e respiratórios e aspectos como a reatividade, e, ao menor sinal de complicações, ocorrem intercessões para melhorar as condições do bebê (Nascimento, 2012).

A condição dos recém-nascidos internados na UTIN não deixa de ser muito especial, já que este tipo de internação, requer a separação da mãe e o bebê. Na maioria dos casos, 0 recém-nascido que necessita dessa unidade, encontra-se entre 0 e 28 dias, é pré-termo ou imaturo. Nestas unidades habitualmente, as visitas pelos pais e familiares são restritas (Costa et al., 2010).

Não obstante a relevância da UTIN, para os neonatos doentes, esta unidade é se traduz em um ambiente nervoso, impessoal e até atemorizado. Este "ambiente é repleto de luzes fortes e constantes, barulho, mudanças de temperatura, interrupção do ciclo do sono, visto que são necessárias repetidas avaliações e procedimentos, acarretando, desconforto e dor" (Reichert et al., 2007, p.3).

Os efeitos da hospitalização são marcantes para o bebê, pois, esses têm que superar o isolamento da mãe e ainda tolerar procedimentos, quase sempre, hostis e dolorosos (Morais, \& Costa, 2009). São marcantes ainda para os pais, que ficam ansiosos com o próprio ambiente, a perda de peso do bebê, o desconhecimento do diagnóstico, o uso de leite artificial, quando necessário, e a alta da mãe deixando o recém-nascido na UTI que é a principal fonte de ansiedade para os pais (Nascimento, 2012).

A complexidade dos cuidados prestados na UTIN exige profissionais capacitados a realizar procedimentos que podem fazer a diferença entre a vida e a morte. Requer do 
profissional resiliência para lidar com o ruído emitido pelos aparelhamentos, às coletas ou punções complicadas, insuficiência respiratória em recém-nascidos com doenças graves e terminais, esclarecer diagnósticos e vivenciar o sofrimento da família. Há ainda a dificuldade em lidar com a morte em um ambiente em que se espera bebês nascidos com saúde, vez que quando ocorre um óbito, esmaecem sonhos idealizados pelos pais à criança (Nascimento, 2012).

Os cuidados oferecidos aos pacientes, quase sempre, são guiados pelos valores das máquinas ficando absortos na doença. Este ambiente produz um estresse muito grande sobre a equipe de enfermagem, uma vez que, além de vivenciar situações de morte e de vida, a equipe deve se relacionar com a neonato, seus pais ou acompanhantes. A equipe deve estar alerta para a exatidão de suas ações e para não atribuir uma supervalorização da tecnologia em avaria dos cuidados prestados ao paciente (Santana et al., 2009).

Os profissionais que lidam com as UTI's ficam muito envolvidos com procedimentos e monitores (Costa et al., 2009). O cotidiano intenso deste ambiente pode levá-los a serem mais técnicos em suas ações (Villa, \& Rossi, 2002). Por isso, a equipe de enfermagem deve estabelecer uma relação profissional-paciente provida de qualidade. Isso significa acolher as ansiedades do ser exposto ao outro que cuida e, que requer o comparecimento solidário do profissional de saúde, que deve estar municiado de habilidade científica e humana para lidar com estas situações (Carvalho et al. 2005).

A assistência de enfermagem na UTIN deve oferecer subsídio ao recém-nascido considerando-o como um ser biopsicossocioespiritual. Isso requer o cuidado dos profissionais e a presença da mãe, a qual configura fonte de segurança para o recém-nascido, tornando-se imprescindível para o enfrentamento da realidade. Espera-se uma atenção em saúde capaz de priorizar o ser criança, e, o ser mãe ou responsável acompanhante, propondo-se um cuidado em que profissionais de enfermagem, norteiem as suas práticas para atender diferentes necessidades de ambos (Morais, \& Costa, 2009).

\section{METODOLOGIA}

Essa pesquisa pretendeu fazer um estudo para definir a incidência de óbitos ocorridos em neonatos por sepse de pacientes internados em UTI Neonatal entre os anos de 2013 a 2017, na região de Patos de Minas - MG, situado na região intermediária do Triângulo Mineiro e Alto Paranaíba. Abrange uma área territorial em $\mathrm{Km}^{2}$ de 3.189,769 e com uma população de 150.833 habitantes. Os estabelecimentos que atendem neonatos nessa região são 02 hospitais públicos e 01 de atendimento privado (IBGE 2018).

Tratou-se de um estudo de natureza documental, descritiva e analítica, de abordagem quantitativa, que foi realizada através da avaliação dos dados contidos no banco de dados- 
DATASUS-SIHD, da Secretaria Municipal de Saúde de Patos de Minas - Vigilância Epidemiológica.

O sistema DATASUS é de acesso público com a disponibilização das bases de dados sobre morbidade hospitalar e de acesso livre para consultas e checagem das causas que levam a internações. O SIHD é um sistema de informações hospitalar descentralizado disponibilizado pelo DATASUS - Ministério da Saúde, onde é realizado o processamento e faturamento das autorizações de internações hospitalares dos hospitais públicos e privados conveniadas ao SUS, e as bases de dados remetidas mensalmente ao DATASUS para que sejam aprovados e realizados os pagamentos dos procedimentos executados durante a internação. Os dados foram coletados entre os meses de maio a julho de 2018 onde foram copilados todos os óbitos ocorridos em neonatos por sepse.

\section{RESULTADOS E DISCUSSÃO}

De acordo com o gráfico 1 a sepse neonatal é uma das causas principais dos óbitos neonatais entre os anos 2013 a 2017.

Gráfico 1. Frequência de óbitos infantis em residentes no município de Patos de Minas de acordo com o tipo de gravidez da mãe e das cinco principais causas, 2013-2017

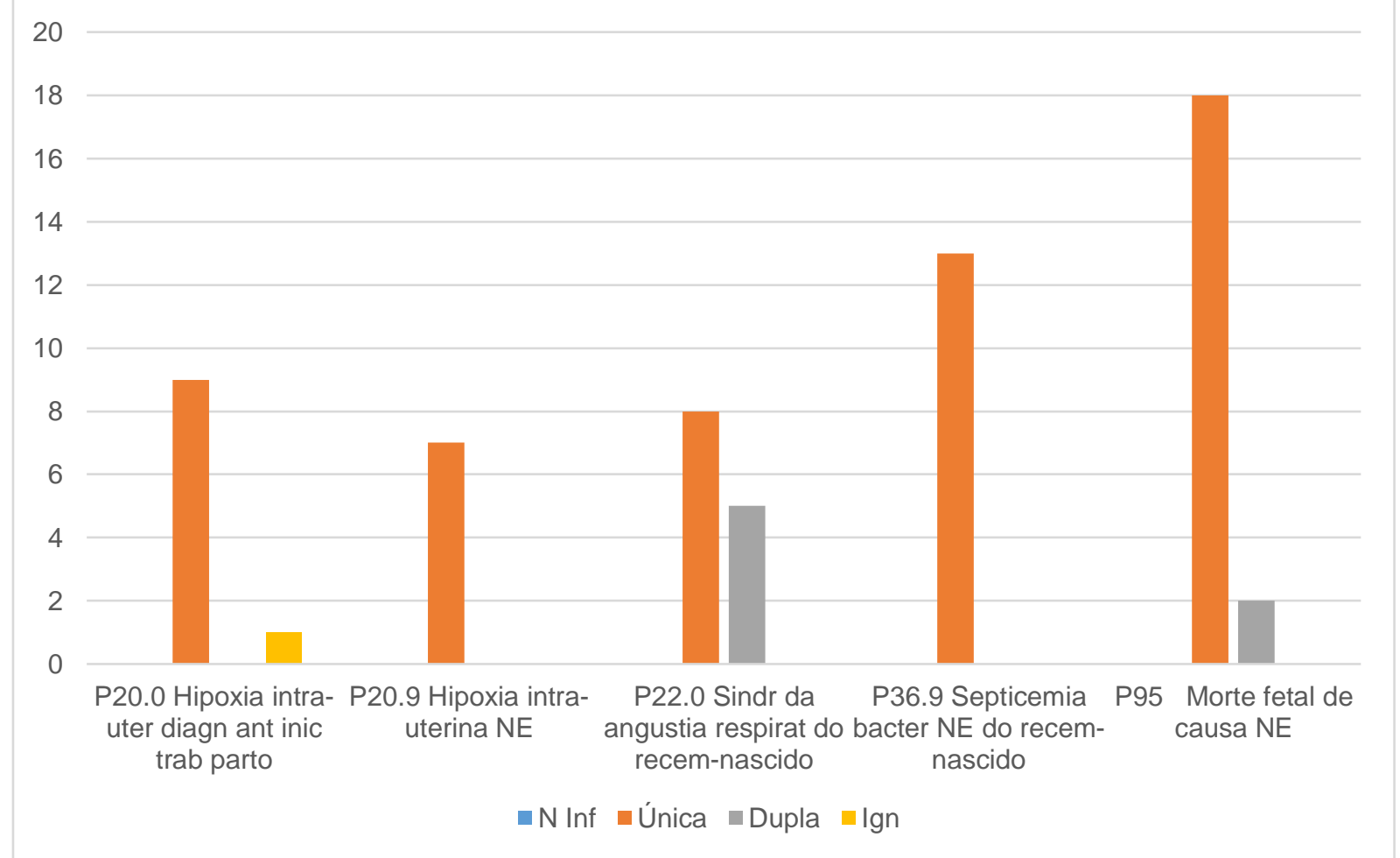

Fonte: Elaborado pelas autoras (2018)

Rev. Psicol Saúde e Debate. Dez., 2018:4(3):20-31. 
O estudo de Santos (2017) confirma que a sepse é uma causa importante de mortalidade e morbidade em neonatos. No mundo atribuem-se às infecções neonatais cerca de $23,4 \%$ das mortes registradas em neonatos. Em países subdesenvolvidos, a sepse é responsável pela morte de $30-40 \%$ dos neonatos.

Castro (2017) alerta que estimativas de sepse são preocupantes não apenas nos países em desenvolvimento, mas também nos desenvolvidos. A incidência mundial da sepse neonatal "varia de 7,1 a 38 por 1000 nascidos vivos na Ásia, de 6,5 a 23 por 1000 nascidos vivos na África e de 3,5 a 8,9 por 1000 nascidos vivos na América do Sul e Caribe. Nos Estados Unidos e Austrália, fica em torno de 6,0 a 9,0 por 1000 nascidos vivos" (p.10). Mas, a incidência da sepse neonatal pode variar e depender de particularidades dos recém-nascidos como peso ao nascer, idade gestacional e pós-natal, também se sujeita a métodos assistenciais, aos procedimentos de avaliação diagnóstica e aos protocolos de vigilância relacionados a cada Unidade. A sepse tardia apresenta como maior fator de risco o baixo peso ao nascer, a prematuridade, infecções precedentes, condição nutricional, uso de ventilação mecânica, cateteres vasculares, nutrição parenteral, relaciona-se ainda à infraestrutura da unidade e sua superlotação.

O Gráfico 2 demonstra que o sexo masculino tem uma maior prevalência nos óbitos neonatais.

Gráfico 2. Frequência de óbitos infantis em residentes no município de Patos de Minas, por sexo, de acordo com as cinco principais causas, 2013-2017 - Prevalência do sexo masculino

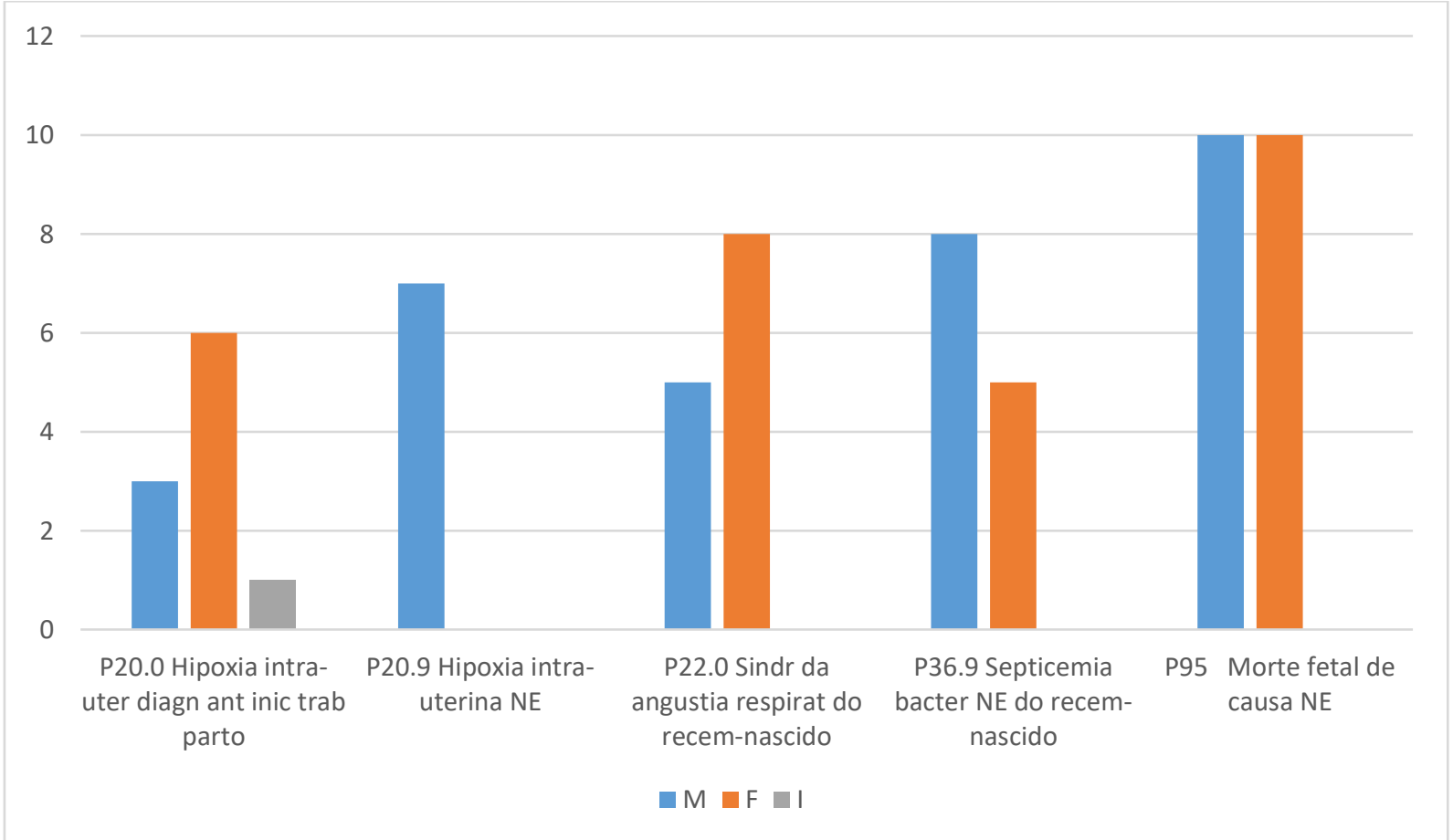

Fonte: Elaborado pelas autoras (2018)

Rev. Psicol Saúde e Debate. Dez., 2018:4(3):20-31. 
Mattos e Chiaradia (2013) informam que os recém-nascidos do sexo masculino podem apresentar até quatro vezes mais probabilidade de desenvolver sepse, isso porque, é no cromossomo "X" que se encontra um gene associado à síntese de lgM. Segundo Canhas (2009), a IgM é a imunoglobulina principal da resposta primária aos antígenos, bem como é a primeira classe a se elevar em fases agudas dos processos imunológicos.

Em correspondência Campos et al. (2010) observaram, em seu estudo, em relação ao sexo um equilíbrio na repartição dos recém-nascidos sépticos. Mas, conforme estes autores, de fato, a literatura alude uma predisposição ao desenvolvimento de sepse neonatal para o sexo masculino.

O Gráfico 3 demonstra que os óbitos neonatais ocorrem do $7^{\circ}$ ao $27^{\circ}$ dia de nascimento. Gráfico 3. Frequência de óbitos infantis em residentes no município de Patos de Minas, por faixa etária das cinco principais causas, 2013-2017. Período de ocorrência de óbitos neonatais

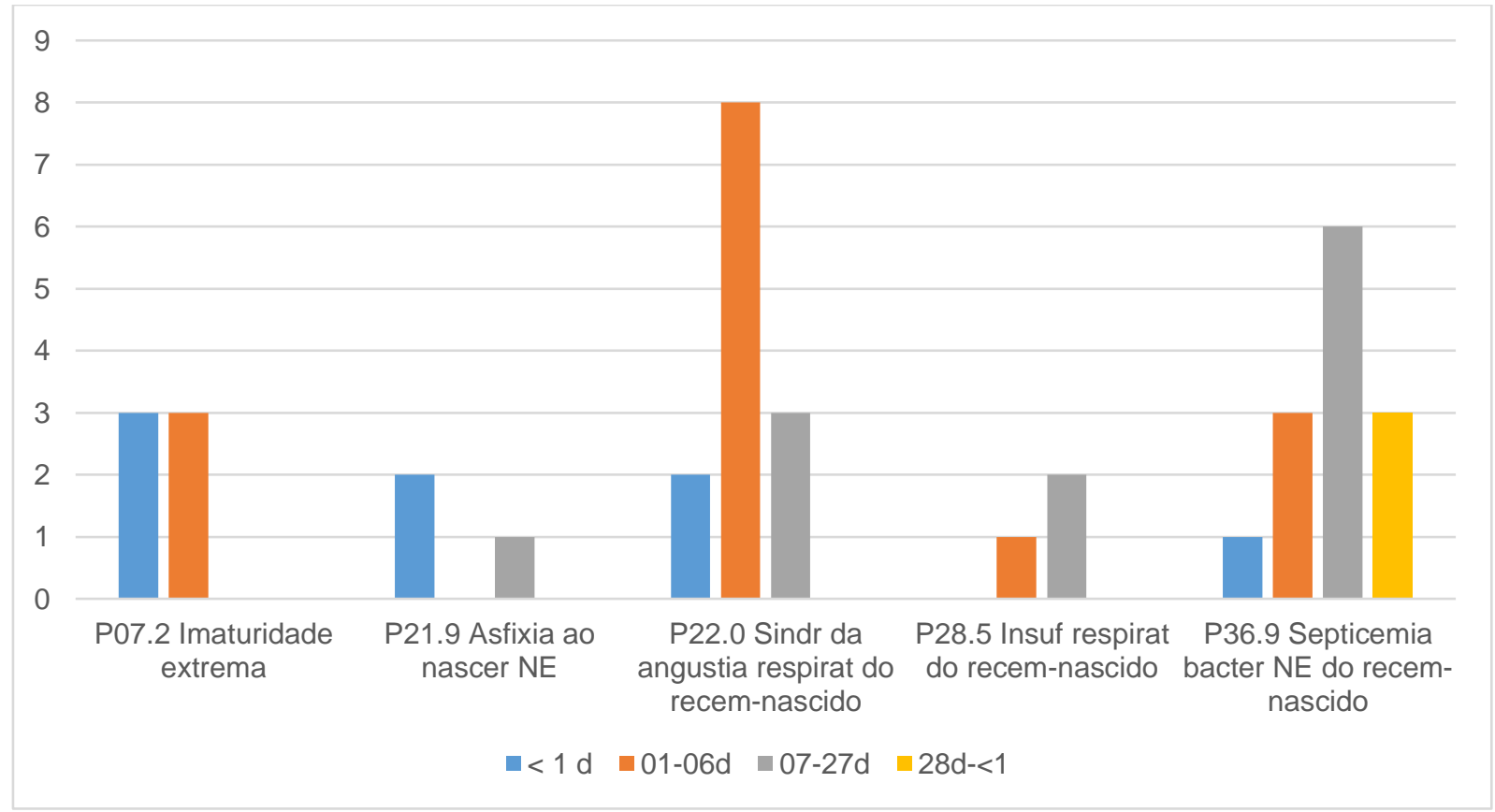

Fonte: Elaborado pelas autoras (2018)

No estudo de Costas et al. (2010) pode-se verificar que, na maioria dos casos, o recémnascido que necessita de uma UTIN encontra-se entre 0 e 28 dias, é pré-termo ou imaturo (Costa et al., 2010).

Estima-se que, anualmente, ocorram quatro milhões de mortes devido à sepse neonatal no mundo, principalmente dentro de UTI, tida como um dos problemas mais expressivos de saúde pública em países em desenvolvimento, em razão da escassez de recursos financeiros para prevenção e controle de infecções hospitalares, bem como pelos elevados custos com a hospitalização (Barbosa et al., 2007). 
O Gráfico 4 demonstra que a prematuridade do parto interfere na condição clínica do neonato.

Gráfico 4. Frequência de óbitos infantis em residentes no município de Patos de Minas, de acordo com a duração da gestação das cinco principais causas, 2013-2017 - Interferência da prematuridade na condição clínica do neonato.

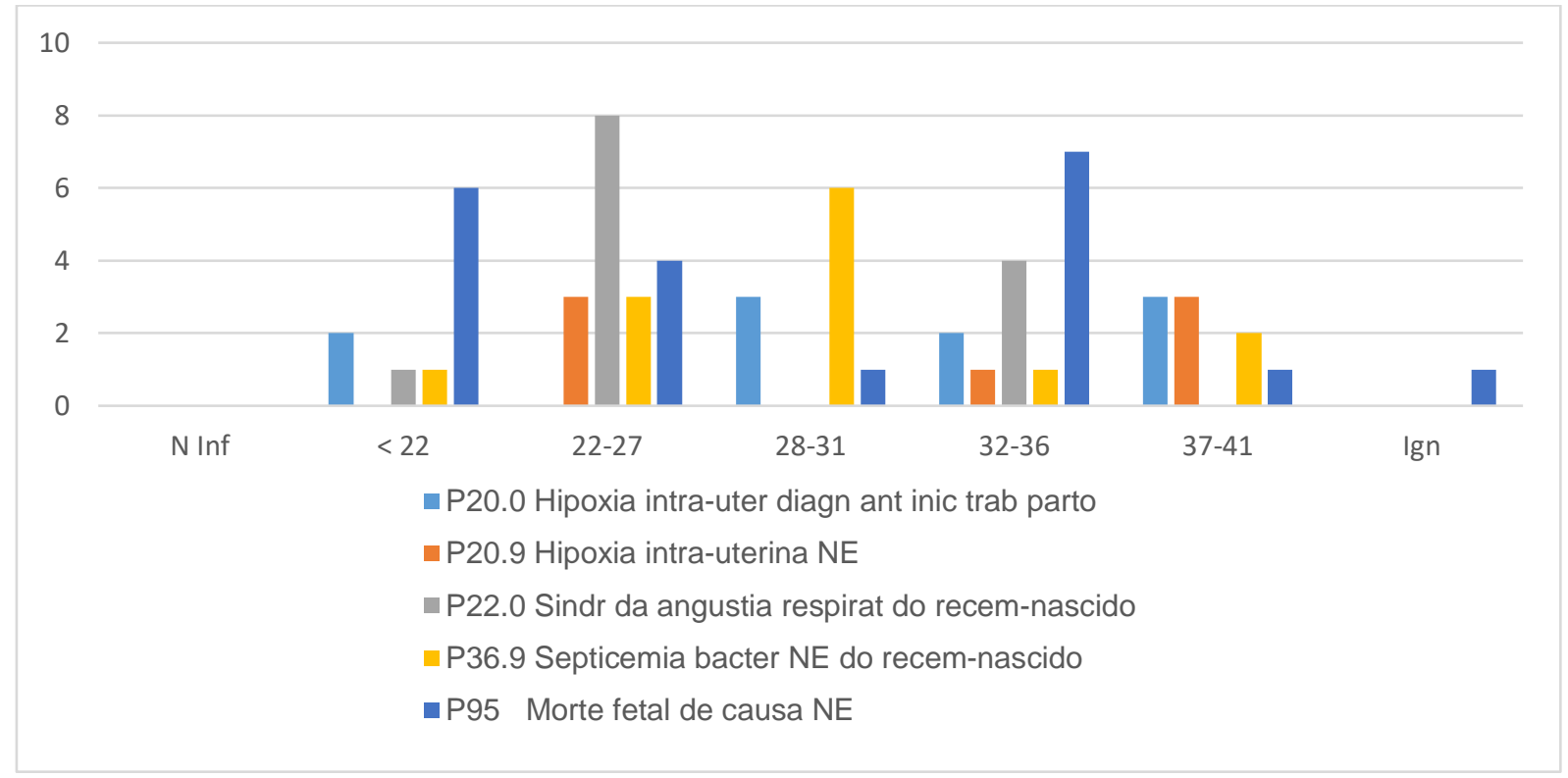

Fonte: Elaborado pelas autoras (2018)

Referente as manifestações clínicas no recém-nascido, Silveira e Procianoy (2012) afirmam que nem sempre estas são especificas, por isso, torna-se necessário associar os fatores de risco maternos e neonatais para se levantar suspeitas de sepse e partir para investigar exames laboratoriais no recém-nascido. Mas, há evidências clínicas mais claras que contribuem para sistematizar o diagnóstico de sepse neonatal na ausência de germe, como: "instabilidade térmica, dificuldade respiratória, hipotonia e convulsões, irritabilidade e letargia, sintomas gastrintestinais, icterícia idiopática, palidez, sangramentos e até uma avaliação subjetiva" (bebê que aparenta não estar bem). (p.30). Os principais fatores de risco associados às mães e aos recém-nascidos, podem ser:

- Materno: Febre materna $\left(>37,5^{\circ} \mathrm{C}\right)=$ Recém-nascido: Taquicardia fetal (> $\left.180 \mathrm{bat} / \mathrm{min}\right)$

- Materno: Infecção urinária no parto = Recém-nascido: Prematuridade

- Materno: Colonização por Streptococcus agalactiae = Recém-nascido: Apgar 5 min $<7$

- Materno: Ruptura das membranas (> 18 horas) = Recém-nascido: Sexo masculino

- Materno: Infecção do trato genital (coriamnionite, líquido fétido, leucorreia, herpes) = Recém-nascido: Primeiro gemelar (?)

Rev. Psicol Saúde e Debate. Dez., 2018:4(3):20-31. 
Mattos e Chiaradia (2013) explicam que, em casos de sepse, a prematuridade associada à deficiência imunológica acentuada, tem risco aumentado quando associada à colonização materna por EGB (Estreptococos do grupo B) e à amniorrexe prolongada.

Santos (2017) já afirma que a sepse em recém-nascidos pré-termo de importante baixo peso (RNPTMBP) pode ser fatal em razão do diagnóstico difícil e tardio.

Pinheiro et al. (2007) buscaram identificar os fatores de risco maternos relacionados à sepse neonatal precoce, analisando vaginose bacteriana, micro-organismos isolados em cultura de urina materna e na hemocultura do recém-nascido na sala de parto. A amostra contou com 302 mães e seus bebês que foram acompanhados até sete dias de vida, para diagnosticar a sepse. Os autores diagnosticaram 16 casos de sepse neonatal precoce e chegaram aos seguintes resultados: o Streptococcus agalactiae foi o principal micro-organismo isolado na hemocultura dos recém-nascidos; e a ausência de continuidade pré-natal e baixo peso ao nascer foram os fatores de risco mais importantes para a ocorrência de sepse neonatal precoce.

Silveira e Procianoy (2012) alertam que ao conhecer os fatores de risco da infecção precoce ou tardia, há possibilidade de se propor estratégias preventivas de infecção. Seguramente, uma das estratégias mais significativas é a prevenção da prematuridade. Outras estratégias significativas para prevenir sepse precoce é o uso de medicações competentes a prevenir doenças ocasionadas por patógenos específicos e a inserção de antibioticoterapia materna intraparto.

Freitas et al. (2016) já defendem que para a prevenção da sepse tardia deve-se atentarse aos princípios de controle da infecção hospitalar: área física adequada da Unidade Neonatal; manutenção de recursos humanos habilitados e, em quantidade adequada, demanda; constituir preceitos operacionais e de assistência, adotar minimamente dieta enteral; motivar o aleitamento materno e solicitar presença da mãe para acompanhar os cuidados; restringir o uso de antimicrobiano e para prevenir contra Streptococcus do gupo B todas as gestantes entre 35 e 37 semanas devem ser avaliadas por meio de cultura reto-vaginal.

A Sepse neonatal precoce está intimamente ligada às condições clínicas da mãe e da qualidade do pré-natal realizado pela gestante, muitos fatores de risco estão ligados à detecção precoce de infecções urinárias e as vaginoses bacterianas.

\section{CONSIDERAÇÕES FINAIS}

O presente estudo permitiu constatar que a sepse é uma importante causa de óbito em pacientes neonatos podendo ser classificada como sepse precoce que procede da contaminação do recém-nascido por bactérias transmitidas no canal de parto ou de bacteremias maternas, e a sepse tardia que é a grande responsável pela mortalidade de recém-nascidos internados nas

Rev. Psicol Saúde e Debate. Dez., 2018:4(3):20-31. 
unidades de terapia intensiva. Na pesquisa realizada, mostrou-se que os altos índices de neonatos internados em CTI neonatal pode ser atribuída à assistência pré-natal oferecida às mães, o que pode explicar o alto índice de partos prematuros devido a não detecção dos problemas maternos ou do neonato durante o pré-natal.

A assistência materna adequada pode contribuir efetivamente para prevenir doenças na mãe, que são capazes de levar à prematuridade e às diferentes infecções que oferecem riscos para desenvolver uma sepse. Ocorre que na vida uterina e/ou em seu nascimento, o feto acaba por ficar exposto à contaminação por microrganismos presentes no canal de parto, procedentes da flora genital materna. Igualmente, os ambientes hospitalares ou domiciliares podem ser responsáveis pela colonização de bactérias agentes de sepse, levando a endemias de sepse neonatal.

Conclui-se ser de suma relevância que os profissionais atuantes em UTIs Neonatais sejam hábeis a identificar de modo rápido e adequado se a sepse neonatal é precoce ou tardia, para que, assim, possam garantir que os recém-nascidos recebam um tratamento favorável às suas vidas.

\section{REFERÊNCIAS}

Barbosa, N. G., Reis, H., Resende, D. S., Alvares, J. R., Abadallah, V. O. S., \& Gontijo Filho, P. P. (2007). Sepse neonatal precoce em unidade de terapia intensiva neonatal de um hospital universitário terciário. Pediatria Moderna. 14(50), 186-192.

Benincá, V. M., Milioli, D. P., Madeira, K., Simon, C. S., Pires, M. M. S., Rosa, M. I., \& Simões, P. W. T. A. (2013). Perfil epidemiológico dos óbitos por sepse neonatal na macrorregião Sul de saúde catarinense no período de 1996 a 2009. Arquivos Catarinenses de Medicina, 42(2), 20-26.

Campos, D. P., Silva, M. V., Machado, J. R., Rodrigues, V., \& Barata, C. H. C. (2010). Sepse neonatal precoce: níveis de citocinas no sangue de cordão umbilical no diagnóstico e durante o tratamento. Jornal de Pediatria, 86(6), 509-514.

Canhas, I. (2009) Anticorpos. Portal Infoescola. Recuperado em 19 agosto, 2018, de https://www.infoescola.com/sistema-imunologico/anticorpos/.

Castro, R. S. A. P. (2017). Análise da sepse neonatal tardia em prematuros de muito baixo peso após a implantação do protocolo de sepse na unidade. Dissertação, Faculdade de Medicina da Universidade Estadual Paulista, Botucatu, São Paulo, Brasil.

Carvalho, P. R. A., \& Trotta, E. A. (2003). Avanços no diagnóstico e tratamento da sepse. Jornal de Pediatria, 79(2), 195-204.

Carvalho, A. R. S., Pinho, M. C. V., Matsuda, L. M., \& Scoch, M. J. (2005). Cuidado e humanização na enfermagem: reflexão necessária. Resumos Seminário Nacional Estado e 
Políticas Sociais no Brasil. Recuperado em 08 agosto, 2018, de http://cacphp.unioeste.br/projetos/gpps/midia/seminario2/trabalhos/saude/msau16.pdf

Costa, S. C., Figueiredo, M. R., \& Schaurich, D. (2009). Humanização em Unidade de Terapia Intensiva Adulto (UTI): compreensões da equipe de enfermagem. Interface,13(1), 571- 580.

Costa, M. C. G., Arantes, M. Q., \& Brito, M. D. C. A. (2010). UTI Neonatal sob a ótica das mães. Revista Eletronica de Enfermagem, 12(4), 698-704.

Ceccon, M. E. J. R., Krebs, V. L. J., \& Vaz, F. A. C. (2000). Sepse no período neonatal. Pediatria Moderna. 1(1), 1-5.

Freitas, C. B. S., Teixeira, G. M., Lana, P. P., Zopelaro, B. A., \& Pinto, E. S. O. (2016). Sepse neonatal: fatores de risco associados. Revista Científica Univiçosa, 8(1), 883-889.

Goulart, A. P., Valle, C. F., Dal-Pizzol, F., \& Cancelier A. C. L. (2006). Fatores de risco para o desenvolvimento de sepse neonatal precoce em hospital da rede pública do Brasil. Revista Brasileira de Terapia Intensiva, 18(2), 148-153.

Mattos, D. K., \& Chiaradia, M. V. C. (2013). Sepse neonatal. Pediatria Moderna, 37(1), 1-14.

Morais, G. S. N., \& Costa, S. F. G. (2009). Experiência existencial de mães de crianças hospitalizadas em Unidade de Terapia Intensiva Pediátrica. Revista da Escola de Enfermagem da USP, 43(3), 639-646, 2009.

Nascimento, M. M. (2012). UTI Neonatal: Ambiente de Expectativas ou de Estresse? Recuperado em 13 agosto, 2018, de://artigos.psicologado.com/atuacao/psicologiahospitalar/uti-neonatalambiente-deexpectativas-ou-de-estresse\#ixzz2hQDBIHeX.

Pinheiro, R. S., Ferreira, L. C. L., Brum, I. R., Guilherme, J. P., \& Monte, R. L. (2007). Estudo dos fatores de risco maternos associados à sepse neonatal precoce em hospital terciário da Amazônia brasileira. Revista Brasileira de Ginecologia e Obstetricia, 29(8), 387-95.

Reichert, A.P.S., Lins, R.N.P., \& Collet, N. (2007). Humanização do Cuidado da UTI Neonatal. Revista Eletrônica de Enfermagem, 9(1), 200-213.

Sales Júnior, J. A. L., David, C. M., Hatum, R., Souza, P. C. S. P., Japiassú, A., Pinheiro, C. T. S., Friedman, G., Silva, O. B., Dias, M. D., Koterba, E., Dias, F. S., Piras, C., \& Luiz, R. R. (2006). Sepse Brasil: Estudo Epidemiológico da Sepse em Unidades de Terapia Intensiva Brasileiras. Revista Brasileira de Terapia Intensiva, 18(1), 9-17.

Salicio, D. M. B., \& Gaiva, M. A. M. (2006). O significado de humanização da assistência para enfermeiros que atuam em UTI. Revista Eletrônica de Enfermagem, 08(03),370 - 376.

Santana, J. C. B., Lima, J. E., Matos, T. G., \& Dutra, B. S. (2009). Humanização do cuidar em uma unidade de terapia intensiva adulto: percepções da equipe de enfermagem. Revista Enfermagem UFPE, 3(1), 1-10.

Santos, A. O. (2017). IL-1ß urinário como biomarcador preditivo de sepse neonatal em prétermos. Dissertação de Mestrado, Universidade Federal de Uberlândia, Uberlândia, Minas Gerais, Brasil.

Rev. Psicol Saúde e Debate. Dez., 2018:4(3):20-31. 
Silva, S. M. R., Cunha, M. L. C., Schardosim, J. M., Nunes, C. R., \& Motta, G. C. P. (2015). Sepse neonatal tardia em recém-nascidos pré-termo com peso ao nascer inferior a $1.500 \mathrm{~g}$. Revista Gaúcha Enfermagem, 36(4), 84-9.

Silveira, R. C., \& Procianoy, R. S. (2012). Uma revisão atual sobre sepse neonatal. Boletim Científico de Pediatria, 1(1), 29-35.

Souza, I. F.F.T. (2015). Sepse Neonatal: diagnóstico e tratamento. Monografia de Especialização, Faculdade São Lucas, Porto Velho, Rondonia, Brasil.

Villa, V. S. C., \& Rossi, L. A. (2002). O significado cultural do cuidado humanizado em Unidade de Terapia Intensiva: "muito falado e pouco vivido". Revista Latino-Americana de Enfermagem. 10(2), 137-144. Recuperado em 18 agostos, 2018, de http://www.scielo.br/pdf/rlae/v10n2/10506.pdf. Acesso: ago. 2018. 